\title{
Irritation expertise
}

\section{Recipient design as instrument for strategic reasoning}

\author{
Marc Mölders
}

Received: 4 September 2013 / Accepted: 19 November 2013 / Published online: 11 December 2013

(C) The Author(s) 2013. This article is published with open access at Springerlink.com

\begin{abstract}
The contribution at hand puts forward the notion of "irritation expertise": knowing how to push others into a direction not chosen voluntarily. This kind of knowledge, I will argue, is of particular importance when players in policy contexts try to influence each other by providing futureoriented knowledge that is inherently uncertain. Yet, it is striking that comparatively little attention has been drawn to the question how to reach specific addressees; this is what media studies and conversation analysis call "recipient design". Presenting the example of ProPublica, a US investigative journalism newsroom, illustrates what irritation expertise as instrument for policy development and strategic reasoning means. ProPublica deals with very different formats-from research reports to comic strips - depending on whose behavior it intends to change-from decision-makers to the (general) public. Discussing what Futures Research may learn from this practice concludes this contribution.
\end{abstract}

Keywords Foresight · Investigative journalism · Irritation · Recipient design $\cdot$ Attention-grabbing $\cdot$ Participation

\section{Introduction}

Understanding Futures Research (FR) as instrument for policy development and strategic reasoning points to a special kind of this approach. This means to draw attention to foresight and forward looking activities that seek to change policy-making in a certain way.

M. Mölders $(\square)$

Faculty of Sociology, Law \& Society Unit, Bielefeld University, POB 100131, 33501 Bielefeld, Germany

e-mail: marc.moelders@uni-bielefeld.de

URL: http://www.uni-bielefeld.de/soz/personen/moelders/
Obviously, to move decision makers with the help of FR is a tricky business. Its results usually relate to and will prove right or wrong in the remote future. The promoted change for the better envisages the well-being of future generations or societies. The proposed changes to achieve these betterments, though, relate to the current way of policy development. While these constraints with regard to the relation of shortterm costs and long-term benefits are well-documented, another more general barrier within the realm of policy advising comes on top.

Policy-making's information processing differs considerably from, for instance, science's in general or FR's in particular. There are other aspects that count, relevant information is filtered by distinct criteria, attention spans differ, etc. Problems resulting from these differences are also wellknown. Voß \& Kemp designate these forms of idiosyncrasy as "the vicious circle of first-order reflexivity" [1]. Sociological systems theory [2,3] describes the political system, science, law, economy, etc. as self-referential communication systems that can adapt to any external influence only by operational criteria which they define themselves [4]. In short, with regard to policy advice this means that any FR result cannot simply be taken over by decision makers. Knowing these fundamental barriers must not hinder from trying to induce changes and does not prevent from successfully doing so. It calls for taking into account these differences in order to increase the likelihood of these attempts. ${ }^{1}$ In order to do this, the concept of "irritations" is introduced in "Introduction". Irritations account for the impossibility of direct interventions, but differ from other external disturbances in being able to make its targets reflect upon routines. In "The concept of irritations" two types of promising irritations are elaborated on - promising with regard to be taken up by a "focal system".

\footnotetext{
${ }^{1}$ For more on past and present approaches to steering in terms of differentiation theories see Mölders [5].
} 
This term again refers to the assumption that addressees process information in a distinct and self-referential way.

These introductory remarks already imply that there are two distinct types of relevant knowledge when the relation of FR and policy development is at stake. An obvious dimension refers to the knowledge needed to make a valuable contribution to FR (the "quality dimension"). Although one may concede that gaining certain knowledge concerning the future is epistemologically impossible, future-oriented propositions can be more or less skillfully substantiated. Whatever the concrete result of a FR enterprise (reports, scenarios, prognoses, visions etc.) may be, its quality (and the quality of the process it was produced in) can be assessed regardless of whether or not the future will be the way a FR approach had foreseen it. The quality of a prognosis is not tantamount to its accuracy. A poorly crafted prediction, on the other hand, may become true. This is why Grunwald [6] or Ferrari et al. [7] propose to assess visions or the like by the quality of their ingredients and recipes that are measurable in the present, for instance, whether or not they argue coherently. Without denying that this obviously is a relevant dimension for FR as instrument for policy development, I will try to draw attention to another type of knowledge. The thesis is that there is a certain and distinct kind of knowledge needed to attract the attention of decision makers and other relevant addressees, which again is constitutive to possibly facilitate changes (the "attention dimension").

The contribution at hand puts forward the notion of "irritation expertise": knowing how to push others into a direction not chosen voluntarily, e.g. with the help of uncertain knowledge. In their famous primer on conversation analysis, Sacks et al. define recipient design as "a multitude of respects in which the talk by a party in a conversation is constructed or designed in ways which display an orientation and sensitivity to the particular other(s) who are the co-participants" [8]. Although this concept was originally developed to reconstruct conversations between co-present speakers, it turns out to be a useful notion for examining FR's way of approaching its addressees.

Presenting the example of ProPublica (PP), a US investigative journalism newsroom, illustrates what irritation expertise as instrument for policy development and strategic reasoning means. PP deals with very different formats-from research reports to comic strips - depending on whose behavior it intends to change-from decision makers to the (general) public. Discussing what FR may learn from this practice concludes this contribution.

\section{The concept of irritations}

What Voß \& Kemp called "the vicious circle of first-order reflexivity" refers to automatisms of executing problem- solving routines. Economy, for instance, cannot respond in any other way to political interventions than in terms of payments or budgets. Law automatically checks political communications with regard to their lawfulness etc. Whether these foreign communications make sense for others (e.g. for society as a whole) cannot be processed; this is why the authors qualify it as a vicious circle.

This diagnosis points to the reason for the decline of theories of steering that rested on "first-order cybernetics" [9]. Policy makers (as well as theorists) had to discover that the "objects of steering" were not controllable by means of target/actual-comparisons but reacted in a very own and unforeseeable way. Not least studies focusing the political steering of science demonstrated this. Van den Daele et al. [10], for instance, showed the manifold ways scientists worked with to translate a political intervention into questions they were able to research on-not because they were unwilling to please political inquiries but because there was a general need of translation. The assumption that science and politics operate differently facilitated the explanation for failing attempts of steering. On the other hand, political initiatives that made scientists work on topics or fields they had not chosen voluntarily (i.e. for scientific reasons) could only do so if a political problem could be taken up scientifically. To cut a long story short: the success as well as the failure of interventions could be explained by differentiating between political and scientific modes of processing.

Thus, if direct interventions render impossible - because any reaction will be according to operational criteria defined by the targets themselves - a concept is needed that takes into account a focal system's idiosyncrasy. This is why the term irritation is a helpful one in this context. Unlike other kinds of external disturbances, irritations are characterized by their quality to make their addressees actually deal with aspects of their environment. ${ }^{2}$ Irritations indicate that the target's usual way of processing information does not work and triggers it to ask why this routine failed. This does not mean that an irritation automatically facilitates the change envisaged by the irritation's "sender". Irritations may be suppressed or the like. However, it works the other way round: If a system should be pushed into a direction it had not chosen on its own, the initiator of this kind of change will need to irritate it. A focal system will only change its usual way of processing, if an irritation is able to indicate a problem of this otherwise smoothly running routine. However, this still remains a problem in the system's own perspective and must not be the same aspect the irritator intended to hint at. To give a simple example, the political system cannot directly push scientists to deliver more applicable knowledge - but it has the opportunity to remind science of this expectation over and over

\footnotetext{
${ }^{2}$ For more on irritations and their relation to a theory of learning see Mölders [11] who builds on Piaget's equilibration theory [12].
} 
again. A failing routine could be a scientific proposal that only accounts for scientific values and its refusal could serve as an irritation that leads the applicant to search for the reasons why something that worked out beforehand no longer does. Here, the reasons are easily comprehensible - they are even handed over in cold print. This example rather intended to shed light on the mechanism. Irritations are hard to reject, being hit by a communication of that kind means to have to spend time and energy for something your environment wants you to.

Yet, it is not easy for an external disturbance to become an irritation. Making a focal system deal with something it otherwise had not, implies a comparatively close proximity to it. Consider Transparency International's (TI) years of demanding for financial institutions to publicly disclose detailed financial information. The information processing of governments could almost automatically reply to be aware of the problem, to do the best they can within domestic boundaries etc. Despite its size and its reputation, TI does not seem to be in a position to irritate in a way that can hardly be ignored. In comparison to the impact the Offshore-Leaks team had on the regulation on banking secrecy in many otherwise restrictive countries, the difference gets striking. ${ }^{3}$

In the next section I will draw on two factors that promote the likeliness of an irritation to have an impact.

\section{Two types of promising irritations}

There are two factors that increase an irritation's likelihood to have an impact on a focal system: (1) a recurring proximity and/or (2) the relevance of its content.

Recurring proximity refers to Teubner's notion of "perturbation channels" in which "impulses for change are not only occasional, punctual and one-sided but merge [...] into a reciprocal perturbation" [13]. Constitutional courts may serve as an illustrating example. Constitutional courts and political decision makers operate so close to each other that communications of the one can hardly be ignored by the other. Apparently, this is an institutionalized perturbation channel in which proximity is being guaranteed. In many other relationships, this kind of proximity has to be produced actively because channels are not institutionalized.

Hutter $[14,15]$ describes the instructive case of "how economy talks the law into co-evolution". In accordance with the remarks concerning the concept of irritation above, Hutter notes that attracting attention of a self-referential entity means to find "messages which become valuable information. [...] New information implies that the screen of the communicating system has to be conditioned in a way which makes it

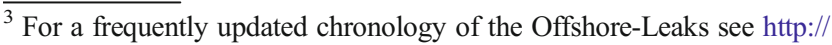
www.icij.org/offshore.
}

receptive to available new messages. Only the response of another system shows whether the attempt has been successful" [15].

In Hutter's case study pharmaceutical companies wanted the legal system to create a pharmaceutical patent law for economic reasons. Several courts worldwide declared for a long time that this request cannot be taken up juridically. Hutter shows that it took decades for the heads of pharmaceutical company patent departments, patent agents and the like to actually produce messages law could be receptive to. In the particular case, the task at hand was to translate the economic question of property rights on certain research results into a question that was internal to the legal system, whether or not life forms could be a patentable subject matter [15]. A crucial switch in this story appeared when the Court of Custom and Patent Appeals (CCPA) announced that the legally relevant distinction would not be the one between living and inanimate things, but between products of nature and human-made inventions.

This is the point at which the economy successfully talked the law into a specific change. In other words and resuming the concept of irritations, here we have a case in which proximity had to be produced. With regard to the kind of knowledge needed to push others into a direction not chosen voluntarily, I would like to call this the "talk-into option".

In the case Hutter reconstructed, it took years and decades to talk the law into the kind of change envisaged by the economy. Yet, the heads of pharmaceutical company patent departments, for instance, did have the opportunity to talk with relevant persons from the legal system. The opportunity to open up interactions that might facilitate a desired change in the long run is not available for anyone. The second factor relevant for turning an easily ignorable disturbance into a promising irritation does not require being close to the target. Once more it is Teubner [16] who proposed a concept showing how to make focal systems receptive to external messages from a distance. However, the condition he formulates is a tough one: the experience of near-catastrophe. Discussing whether or not the recent financial crisis may provide for sufficiently external pressure in order to change the inner constitution of the economy, leads to a possible example of experiencing a near-catastrophe. From the focal system's perspective, this "is not the moment when the self-destructive dynamic causes the abstract danger of a collapse to appear: that is the normal state of things. Instead, it is the moment when the collapse is directly imminent" [16]. Thus, if the content of an irritation is sufficiently catastrophic, it may reach its target even from a distance. Taking a closer look on this mechanism reveals that it is a certain kind of "detour" that compensates for the missing link to a focal system. If the aim is to make an addressee change a usual way of problem solving (more general: of processing information), the shortest detour appears to be publicity. Making known "catastrophic 
behavior" to a relevant and potentially dangerous public may be experienced as a near-catastrophe by an addressee.

This may explain the success of the Offshore-Leaks team compared to the attempts of other civil society organizations. "Tax havens" were known and complained about long before, and yet it needed the publication of an enormous amount of data gathered by investigative journalists to actually effect regulation. The media coverage spread the "news" and the routine several countries executed before - to refer to their regulation on banking secrecy-ran into problems. Seen this way, the journalists succeeded in letting their addressees experience a near-catastrophe. They did not interfere with banks or governments on a direct way. It was the publicity of events with a potential to give rise to public outrage that exerted pressure on financial and political decision makers. Bearing in mind that the leaked data - and their mere quantity - were hardly comprehensible to outsiders, the public itself was used as a more or less empty stopover on this way. This detour turned out to be a shortcut. I would like to call this irritation strategy the "publicity-stopover option".

Coming back to FR's potential impact on decision making, the next session focusses on the (adaptive) Foresight approach. This seems to be an adequate choice as some of its proponents appear to be aware of both distinctions discussed so far: (1) knowledge relevant for the quality of research (the "quality dimension") vs. knowledge needed to attract attention and increase the likelihood of research to be taken up by decision makers (the "attention dimension"). (2) Irritation facilitated by proximity (the "talk-into option") vs. irritation from a distance, facilitated by the experience of nearcatastrophe (the "publicity-stopover option").

\section{The (adaptive) foresight approach}

The initial question of the article at hand was how to design FR as instrument for policy development and strategic reasoning. The argumentation so far made clear that to improve FR's toolbox in order to come to the best possible predictions, the most instructive scenarios or the like (the "quality dimension") can only be one part of the answer. The other part refers to the "attention dimension" of future-oriented knowledge.

The Foresight approach considers itself as a production site of future-oriented knowledge with a clear mission. Havas [17] even suggests that purely analytical studies of possible futures that do not try to connect their findings to possible political actions may not be considered as Foresight. The FORLEARN project " "aimed at consolidating and improving accessibility to Foresight knowledge and know-how, advancing Foresight knowledge and promoting Foresight throughout

\footnotetext{
${ }^{4}$ See http://forlearn.jrc.ec.europa.eu/guide/0_home/about_more.htm
}

Europe." In the context of this project, questions with regard to the impact of Foresight on policy-making played a crucial role.

In their discussion of the results of this project, Da Costa et al. refer to both of the irritation strategies introduced above. Furthermore, the authors choose a common starting point when they note that Foresight and policy-makers are "two communities with different cultures, vocabularies, processes, and time scales" [18]. This corresponds to concepts like "the vicious circle of first-order reflexivity" [1] or "self-referentiality" $[2,3]$ as introduced above.

A general idea to overcome these barriers proposed by $\mathrm{Da}$ Costa et al. is the involvement of policy-makers in the design of Foresight activities. In their elaborations on possible functions Foresight may have in relation to policy-making, they put emphasis on "facilitating policy implementation" [18]. Yet again in accordance with the scope of my contribution, the inclusion of political actors is the answer of the Foresight approach to the challenge "to present the outcomes from the collective process in a way that they are likely to be taken up by policy-making, taking into account its continuouslychanging nature" [18]. Recurring proximity is seen to enable uptake by political decision makers. Within recurring interactions between Foresight practitioners and policy-makers it should be possible to jointly translate the outcomes of Foresight processes into political options. As a crucial condition for the possibility of joint translation activities, Da Costa et al. point to the meaning of "mutual understanding". This again could only emerge through a process of "knowing each other". Exactly corresponding to what Hutter elaborated on, it is defined as "crucial that a joint design phase turns out to be more than just a one-off consultation and becomes a real attempt to build trust and mutual understanding. Much more than the one-way communication of the demand from policymakers to Foresight practitioners, this phase should be conceived in terms of 'joint construction' of demand" [18]. These recurring interactions offer the opportunity to "talk policymakers into considering Foresight matters". Probably, the most important Foresight matter would be the switch of political information processing from short-term urgencies to long-term goals (sustainability etc.).

Not unusual for FR in general, this concept leads to ideas in terms of procedures. Here, it is proposed "to create specific interfaces for translating outcomes from the collective process into policy options" [18]. The collective process refers to other phases of a Foresight exercise. When it is about to explore and to come up with scenarios of possible futures, there should be the opportunity for expert, stakeholder as well as citizen participation. According to the Foresight approach, citizens should especially be involved in making "the fundamental choices" which refer to wider societal goals. This phase is the last but one before the final stage of implementation and coordination in which it is up to Foresight practitioners and 
decision makers to jointly translate the outcomes of the preceding steps.

A specialization of the general Foresight approach has elaborated on the facilitation of policy implementation. Adaptive Foresight adds a "supporting policy definition phase" to the original design of a Foresight exercise $[19,20]$. Again it is emphasized that the decisive task is to translate Foresight results into concrete policy options. In contrast to other concepts, adaptive Foresight proposes a "protected space" for the alignment of Foresight and policy. It is assumed that here policy-makers open up their otherwise hidden agendas and that things might be said that would provoke other ministries or constituencies. On the one hand, Da Costa et al. qualify adaptive Foresight as a "sophisticated step forward in the thinking on how to 'inject' anticipatory intelligence more effectively" [18]. On the other, they also give rise to the concern that protected spaces remind of more expert-driven traditions, whereas Foresight results would be outcomes of participatory processes. With or without protected spaces, aspects like joint translations follow the "talk-into option" in terms of irritation strategies.

Apparently, letting policy-makers experience a nearcatastrophe is inconsistent with their function as sponsors and clients of Foresight exercises. Yet, Da Costa et al. discuss possible ways of "smart communication" in which we find analogies to the "publicity-stopover option". Drawing on theories of signal processing, the authors propose three ways to improve transmission. "Increasing the bandwidth" leads to a greater quantity of information by using parallel signals. With regard to the relation of FR as a sender and policy-makers as recipients, the authors think of "up-to-date attention-grabbing communication tools: coupling qualitative and quantitative information, graphics, YouTube-like videos and other multimedia materials, creative networks, open communities, theatre play, gaming, ambience design, and virtual reality" [18]. Attention-grabbing communication tools most obviously refer to the "attention dimension" of relevant knowledge.

"Improving reception", the second mode of smart communication, provides an even more visible link to the "publicitystopover option". Here, the aim to increase decision makers' attention and concentration is thought to be achieved by connecting FR contents to topics that "recently hit the media in relation to recent threatening events (e.g. good reception of food-safety diseases in times of BSE crisis)" [18]. In line with the theoretical considerations in "The concept of irritations", one might argue that to relate to (near-) catastrophes also increases the likeliness of an irritation to be processed by a focal system.

The last suggestion for improving communication, "optimizing the signal", rather refers to the "quality dimension". It is not about producing more information "but that it is richer in terms of content, or knowledge. This can be done by enhancing its quality, relevance, usability and timing" [18]. The aspect of "timing" is beyond the "quality dimension" and is discussed later on (Investigative journalism as irritation experts).

In summary, it has been shown that (adaptive) Foresight is aware of the differences between the quality and the attention dimension of relevant knowledge. Furthermore, we witnessed that Foresight practically works with both, the publicitystopover as well as the talk-into option. Nevertheless I want to put forward the thesis that FR in general might learn something to improve its impact from another practice: investigative journalism.

\section{Investigative journalism as irritation experts}

Attention-grabbing and facilitating changes in the routines of the most influential societal entities - such as policy-makers, the legal system, or the economy - can be said to be at the core of what investigative journalism does. According to de Burgh investigative journalists "are doing more than disagreeing with how society runs; they are pointing out that it is failing by its own standards. They expose $[\ldots]$ in the public interest, which they define. Their efforts, if successful, alert us to failures in the system and lead to politicians, lawyers and policemen taking action $[\ldots]$ that may result in legislation or regulation" [21].

This definition highlights that impact on a broad scale (societal standards) is what matters most for investigative journalism. If "public interest" serves as a filter to decide whether or not a topic might be worth to pursue, this points to a difference to news journalism in general. Here, a set of values ("newsworthiness" [22]) filters out relevant issues. While news journalism has its own agenda, investigative journalism aims at putting an issue on the agenda (of other media as well as of their targets' agendas) "by saying 'look at this, isn't it shocking!'” [23].

The Offshore-Leaks team obviously succeeded in alerting the public what even resulted in regulatory changes. The "secrets" revealed were communicated as being catastrophic in a way that their mere publicity was sufficient. There was not a special public addressed, in other words: a dedicated recipient design did not seem to be necessary. From FR's perspective it is unlikely to come up with messages of that kind.

The thesis put forward was that FR might learn something to improve its impact from investigative journalism. In order to defend this, I will switch from investigative journalism in general to a special institution: ProPublica (PP). This is an independent newsroom specialized in investigative journalism. Founded in 2008, it became known to a wider public winning two Pulitzer Prizes. The first was won (in collaboration with the New York Times Magazine) in 2010 for Investigative Reporting on urgent life-and-death decisions made by one hospital's exhausted doctors in the aftermath of 
Hurricane Katrina. ${ }^{5}$ The 2011 Pulitzer Prize fell in the category National Report and honored ProPublica's coverage of collateralized debt obligation (CDO) called "The Wall Street Money Machine". This was the first time that such a prize was awarded to stories not published in print. ${ }^{6}$

This success allows PP for only "reporting on stories with significant potential for major impact". ${ }^{7}$ The report on aspects of mercy killings in New Orleans, for instance, had immediate impact. A wider debate on several societal levels got started which quickly led local, state and federal officials to change legislation. ${ }^{8}$ Thus, the main criterion to select stories worth investigating is whether they offer significant potential for major impact. ${ }^{9}$

At first sight, PP seems to operate just like any other investigative journalism newsroom, perhaps only bigger in size. Apart from that, PP's independence may be noteworthy. It is financed by foundations and donations which, as it assures, do not influence editorial processes in order to prevent lobbyism. ${ }^{10}$ This is interesting with regard to Habermas' (1962) [24] claim that modern mass media failed to take up the position of the "fourth estate" because they were thought to shape public opinion by private interests rather than facilitating private reasoning.

The specialty I want to focus on is neither its size nor its funding but rather its recipient design. The Offshore-Leaks team needed no tailoring for having an impact; what they published turned out to be sufficiently catastrophic for the respective focal systems. Given the complexity of issues such as banking secrecy or CDOs, there seems to be no other way but to use publicity as a stopover to irritate the selected targets. Another topic of that kind frequently reported on by PP is hydraulic fracturing. This example elucidates the relation of this organization to what the contribution at hand calls "irritation expertise".

In summer 2008, the State of New York had to decide upon a fracturing project. The respective research done by PP intended to show that the act at issue lead to severe environmental damage. The newsroom made available its investigations to the Times Union for free. This paper was known to be actually read by the representatives. ${ }^{11}$ Thus, it was not just crucial to make something otherwise hidden public but rather to make this known to a relevant public; in this case to those who had to vote for or against the fracturing project at stake.

\footnotetext{
$\overline{{ }^{5} \text { See http://www.pulitzer.org/citation/2010-Investigative-Reporting }}$

${ }^{6}$ See http://www.propublica.org/awards/item/pulitzer-prize-for-nationalaffairs-the-wall-street-money-machine/

${ }^{7}$ See http://www.propublica.org/about/

${ }^{8}$ See http://www.propublica.org/awards/item/pulitzer-prize-ininvestigative-reporting-deadly-choices-at-memorial/

${ }^{9}$ See http://www.propublica.org/about/

${ }^{10} \mathrm{See}$ http://www.propublica.org/about/

${ }^{11}$ See http://www.propublica.org/about/focusing-public-attention-andstaying-with-a-story-relentlessly
}

The mechanism itself is easy to reveal: Politicians are worse off if it is publicly known that they do not care for potential environmental risks. Of course, this can only work out if the topic at stake is a publicly known one and actually causes reservations. Especially as early as 2008, fracturing is unlikely to fit in this category. PP intends to speak "in the public interest" $" 12$ - but maybe the public does not know much about its interest in hydraulic fracturing. In order to awaken interest in such complex issues, it works with formats such as songs ${ }^{13}$, videos, or comic strips. ${ }^{14}$ These are thought to facilitate an easy access to difficult issues and the opportunity to build up an opinion in the further course. In the context of their award-winning coverage of the CDO industry, it also worked with a Broadway Song ("Bet Against the American Dream"). ${ }^{15}$ This idea was created in collaboration with students from New York University (NYU) who were asked to explore ways to attract attention for complex stories. Apparently, PP does not expect that there is one "general public", but rather several publics that are receptive to different formats.

Of course, it is debatable how much content can be conveyed by songs, videos, or comic strips and it generally is difficult to assess impacts of that kind. Furthermore, we cannot claim a causal relation between the interest in a song and the readiness to get involved with a complex issue. Bearing in mind though, what Hutter said with regard to promising irritations - that it is about finding messages which become valuable information in order to be taken up by an addressee-PP can be said to actually design its messages in a manner that pays a lot of attention to enable uptake by its recipients. In terms of the irritation strategies: Obviously, PP is an expert with regard to the publicity-stopover option - not only by publishing data or the like but by finding the right stopovers for the shortest detour (e.g. newspapers read by representatives). The way it seeks to arrest public attention can be described as a special type of talking-into. This already points to a decisive difference; changes of the latter kind take time. According to its self-description, PP emphasizes "being persistent" and to "stay with issues so long as there is more to be told, or there are more people to reach". ${ }^{16}$

To be clear on this point: what PP does may not be described as a more or less neutral awakening of interest. Again the case of hydraulic fracturing illuminates this aspect. Geoscientists' attempts to reduce the number of dangerous

\footnotetext{
${ }^{12}$ This even is this organization's motto: “Journalism in the Public Interest".

${ }^{13}$ An example can be found on http://www.youtube.com/watch?feature= player_embedded\&v=timfvNgr_Q4

${ }^{14}$ An example can be found on http://www.propublica.org/special/cdoworld

${ }^{15}$ This song is available on http://www.propublica.org/article/video-betagainst-the-american-dream

${ }^{16}$ See http://www.propublica.org/about/
} 
liquid substances needed to release petroleum and natural gas are not discussed with the same care. As soon as PP decides to pursue an issue, it takes sides - and be it in the public interest. This makes it hard to avoid one-sidedness and allows for counterarguments that weaken its original strength.

Generally speaking, one may argue that revelations of grievances, on the one hand, and recommendations with regard to future policies, on the other, should not be mixed up. In the next section I will try to point to aspects FR could learn from the (specific) practices of investigative journalism beyond mere imitation.

\section{What FR may learn from PP}

Choosing the publicity-stopover option to irritate policymakers is a risky endeavor for FR. Because of its relative proximity to the political system, FR could be regarded as selfishly undermining its privileged position in the realm of policy advice. If you can talk to decision makers on a direct way, it is suspicious to look for detours. Generally speaking, the success of the publicity-stopover option is dependent on finding a relevant public; this was part of PP's irritation expertise.

At first sight, for FR as instrument for policy development only policy-makers appear to be a relevant recipient. The publicity-stopover option is characterized by indirectly irritating a focal system via a relevant public that is assumed to have an influence on the original target. This seems to imply that a relevant public already exists. Some topics, such as the Offshore-Leaks revelations, may be able to shock any public. With regard to the issues FR is dealing with, this is unlikely. In other words, there is no relevant public available that could serve as a stopover or shortcut. Thus, the first thing FR might learn from PP is how to produce a relevant public with means of recipient design.

A central problem FR has in convincing others is the alleged missing urgency of its recommendations. A first step to work on this perception could be to make public the relation between present decisions and possible futures. The creation of a Futures public is a prerequisite for making use of the publicity-stopover option. This would facilitate to reveal that a certain decision was made at the expense of future generations, societies etc. In order to gradually push decision makers from a short-term to a long-term perspective, a public insisting on such a switch would be helpful.

This leads back to the irritation strategy pursued by PP. Irritations in general disturb the usual way of processing information. It needs something that stops an otherwise smoothly running routine. At the same time, though, this has to be something the target can be receptive to. According to this, PP's recipient design with regard to producing publics is compelling. Trying to interfere with a public whose usual information processing works with rather short-term perspectives, videos, songs, or comic strips may actually facilitate to stop this routine, to think of prioritizing the long-term side. These formats principally allow for being irritated. Think of having seen a movie or the like that truly puzzled you. Often, this turns out to have no long-lasting impact. You exit the cinema and think of other things.

This is why the possibly most important lesson one can learn from PP is to be persistent. In order to really attract public attention, any one-off attempt will not do. For FR this means first and foremost to switch to a long-term orientation itself, to pursue (or: investigate) issues for a considerably long time and not switching from one topic to the next. Hinting at investigation again refers to the "quality dimension" of knowledge that obviously has a time dimension as well.

Resuming the means of "smart communication", Da Costa et al. designated "timing" as a possibility to enhance the quality of FR's input in terms of knowledge ("optimizing the signal"). Although this arguably was considered in another way, timing can as well mean that it might pay off to take more time. The same authors also proposed to make use of "attention-grabbing communication tools" such as graphics, videos and other multimedia materials. Yet, these were thought to irritate policy-makers in terms of the talk-into option and not as a means of preparing a potential stopover.

Producing a public that is interested in FR matters has another effect. Public participation plays a crucial role in the design of foresight activities. Yet, a recurring problem in this context is to find the right public to involve in procedures. Lezaun \& Soneryd [25], for instance, pointed to the dilemma that those parts of the public who are informed and organized are not seen to represent the general public but to pursue their vested interests; those who are unorganized are uninformed and unable to form an opinion. In a similar vein, Bogner [26] points to the paradoxical effect that professionally organized procedures rarely are linked to public controversies, but build a kind of closed laboratory setting.

Looking at PP's recipient design might also offer an opportunity to circumvent the procedural bias of participatory approaches to FR. In the long run, a public whose interest might had been awaken by attention-grabbing communication tools that again facilitated to maintain an involvement with a complex issue, recommends itself for taking part in procedures.

Of course, the creation of a formerly inexistent public is not the only possible stopover. Using (mass) media as disseminators is an obvious alternative. This would mean to convince them of the newsworthiness of FR matters. Thus, talking the media into disseminating FR recommendations yet again needed another kind of recipient design. This refers to FR's newsworthiness and its capacity to connect to values such as proximity, relevance, immediacy, drama and so forth [22].

The term "immediacy" leads over to the question what to do if FR considers some of its recommendations as being 
urgent. We had to concede so far that the talk-into option generally takes time. Furthermore, with regard to the creation of an interested public, the publicity-stopover option might also work out only in the long run. Finally, it comes to obvious risks, if the publicity-stopover option is pursued to shock its target with the experience of a near-catastrophe.

There might be milder versions. Da Costa et al. referred to "improving reception" as another mode of "smart communication". Drawing policy-makers' attention to FR matters could be eased by connecting to topics that recently hit the media, referring to the BSE crisis as an example. This could reduce the risk of incurring the wrath of FR's sponsors and clients as these were forced to deal with the topic at stake beforehand. More generally, talking about catastrophes obscures that the specifically relevant content of a persuasive irritation could be of a positive kind as well. An easy example would be trying to convince policy-makers that focusing on long-term perspectives could serve as a "unique selling proposition" in times of election campaigns.

All of these considerations refer to what the Foresight approach calls "shaping within boundaries" or the traditional "mode 1" of FR. This means that it should be closely connected to action and decision making, mainly targeting public policy. A "mode 2" of FR, on the contrary, seeks to promote fundamental changes in the current system, challenging the boundaries. Such a mode 2 approach would obviously have neither any difficulties in pursuing whatsoever type of using publicity as a stopover and not consider talking policy-makers into something an option.

Pang's notion of "Futures 2.0" can be said to follow such a mode 2 strategy. Unlike Foresight or many other approaches to FR, Pang regards attempts that promote approaching policymakers as a detour. To him, "the people who will shape the twenty-first century ... are ordinary people" [27]. Yet, the problem to overcome the vicious circle of first-order reflexivity remains: "No one will deny that the world needs to think and act as if the future matters. But getting people to do so is a challenge" [27]. In one part of his concept — called "choice architectures and nudges"-Pang describes means of irritating "ordinary people". He sketches on tools that "provide real-time information about users' current states or performance; make visible option they have for changing their behavior; what consequences different choices would have; and even how their performance compares to neighbors or peers" [27]. As an already existing example, he refers to fuel efficiency calculators available in some recent automobiles. Pang then applies these "nudges" on smart houses, for instance, that are able to display how close they are to being carbon neutral, to compare themselves to other houses in the neighborhood etc. [27].

Apart from fairly open questions such as how to program the exact consequences of certain actions or legal objections with regard to surveillance, this leads back to technology design and likewise away from recipient design. In other words, Pang opts for a technological solution to a communicative problem: how to push others (be it ordinary people or social systems) in a direction not chosen voluntarily.

On the contrary, the contribution at hand exclusively focused on communicative problems and solutions which are summarized in the following section.

\section{Conclusions}

Starting with the widely shared assumption that political decision making and scientific research process information in distinct ways, the article at hand pointed to the relevance of the "attention dimension" of future-oriented knowledge. The quality of FR alone will not facilitate an uptake by policy makers. These premises lead to the concept of irritations, meaning communications that make their addressees deal with aspects of their environment. The mere quantity of external disturbances makes it necessary to think of irritation strategies. Two specific options were scrutinized: (1) the talk-into option and (2) the publicitystopover option. The first one is facilitated by recurring proximity. In myriads of interactions the "irritator" tries to formulate messages in a way that can be understood by the focal system. This option takes time but may lead to sustainable kinds of change. For the success of the second option, irritating communications need a specific content. Unlike the first irritation strategy, to make use of publicity as a stopover on the way to a focal system, proximity is not necessary. Making publicly known that the usual way of a target's information processing causes damages (for itself, for society, for the environment), may work out as a shock that makes the focal system reflect this routine.

Subsequently, the (adaptive) Foresight approach was focused on because of its awareness of the attention dimension as a relevant type of knowledge. The concepts developed in this context first and foremost try to catch the attention of policy makers on a direct way. This explains why Foresight and related approaches gained a considerable stock of knowledge with regard to the talk-into option. The publicitystopover option is regarded as a risk to upset the political system in its function as sponsor and client of FR. This option can only work out, if there is something like a relevant public which can hardly be said with regard to FR matters. This is why a certain step back was proposed. In order to awaken public interest in the topics FR deals with, the practice of investigative journalism was scrutinized. Investigative journalism is the societal place that is specialized in using publicity to change routines that cause severe damages.

The analysis of the way the newsroom PP works lead to instructive strategies to awaken public interest. Using attention-grabbing communication tools may indeed work out to create a public that otherwise would not deal with a complex issue. Generally, manifold examples show that public pressure is an excellent means to induce change. In order to 
enable public pressure, there is a need for a substantiated recipient design to reach the public.

For many FR concepts, public participation is a constitutive element. Basically this is implemented in terms of procedures. More or less randomly chosen citizens take part in scenario workshops or the like. The strategies pursued by PP show that sustainability is not just an aim with regard to the output of irritations, but has to be part of the input-side as well. Arousing public interest in a complex issue has to be followed by attempts to maintain this interest. PP offers formats such as songs, videos, or comic strips to attract attention but also publishes their research reports and investigations in order to enable the forming of an opinion in the further course.

This again led to the conclusion to reconsider FR's own long-term orientation with regard to being persistent. For many parts of the public, FR matters seem to be far away from their everyday lives. In order to make futures and the meaning of present decision making for shaping them a public issue, it seems worthwhile to stay with a topic for a considerable time and not to look for the "next big thing" over and over again.

The tools developed by FR allow for a change of its irritation strategies. This contribution proposes to think of switching from directly irritating policy-making to more indirect ways that may take more time but likewise facilitate more sustainable kinds of changes. In more concrete terms, it calls for modes of public participation beyond or at least complementary to procedures. In order to do this, FR can make use of the irritation expertise it already gathered by trying to attract policy-makers attention. Ultimately, the public is the target of anything FR wants the political system to make changes for. Thus, to think of a recipient design that increases the likeliness of complex issues to be taken up by the public does not appear to be a detour after all — and can be done without calling for Futures 2.0.

Open Access This article is distributed under the terms of the Creative Commons Attribution License which permits any use, distribution, and reproduction in any medium, provided the original author(s) and the source are credited.

\section{References}

1. Voß JP, Kemp R (2006) Sustainability and reflexive governance: Introduction. In: Voß JP, Bauknecht D, Kemp R (eds) Reflexive governance for sustainable development. Edward Elgar, Cheltenham, pp 3-28

2. Luhmann N (1995) Social systems. Stanford University Press, Stanford

3. Luhmann N (2012) Theory of society. Volume 1. Stanford University Press, Stanford

4. Febbrajo A, Teubner G (1992) Autonomy and regulation in the autopoietic perspective: An introduction. In: Teubner G, Febbrajo A (eds) State, Law and economy as autopoietic systems. Regulation and Autonomy in a New Perspective. Giuffrè, Milan, pp 3-16

5. Mölders M (2013) Kluge Kombinationen: Zur Wiederaufnahme systemtheoretischer Steuerungskonzepte im Governance Zeitalter. Zeitschrift für Rechtssoziologie 33:5-30

6. Grunwald A (2012) Technikzukünfte als Medium von Zukunftsdebatten und Technikgestaltung. KIT Scientific Publishing, Karlsruhe

7. Ferrari A, Coenen C, Grunwald A (2012) Visions and ethics in current discourse on human enhancement. Nanoethics. doi:10.1007/ s11569-012-0155-1

8. Sacks H, Schegloff E, Jefferson G (1974) A simplest systematics for the organization of turn-taking for conversation. Language 50:696735

9. Easton D (1965) A systems analysis of political life. Wiley, New York

10. Daele W van den, Krohn W, Weingart P (ed) (1979) Geplante Forschung. Vergleichende Studien über den Einfluß politischer Programme auf die Wissenschaftsentwicklung. Suhrkamp, Frankfurt a. M

11. Mölders M (2011) Die Äquilibration der kommunikativen Strukturen: Theoretische und empirische Studien zu einem soziologischen Lernbegriff. Velbrück, Weilerswist

12. Piaget J (1985) The equilibration of cognitive structures: The central problem of intellectual development. The University of Chicago Press, Chicago

13. Teubner G (2002) Idiosyncratic production regimes: Coevolution of economic and legal institutions in the varieties of capitalism. In: Ziman J, Boden MA, Wheeler M (eds) The evolution of cultural entities. Oxford University Press, Oxford, pp 161-182

14. Hutter M (1989) Die Produktion von Recht. Eine selbstreferentielle Theorie der Wirtschaft, angewandt auf den Fall des Arzneimittelpatentrechts. Mohr, Tübingen

15. Hutter M (1992) How the economy talks the law into coevolution. an exercise in autopoietic social theory. In: Teubner G, Febbrajo A (eds) State, Law and economy as autopoietic systems. Regulation and autonomy in a New perspective. Giuffrè, Milan, pp 265-293

16. Teubner $\mathrm{G}$ (2011) A constitutional moment? the logics of 'hitting the bottom'. In: Kjaer PF, Teubner G, Febbrajo A (eds) The financial crisis in constitutional perspective: The dark side of functional differentiation. Hart, Oxford, pp 9-51

17. Havas A (2005) Terminology and methodology for benchmarking foresight programmes. prepared for the forsociety project, Tasks 1.4 and 3.1. Budapest. http://www.tekno.dk/pdf/projekter/forSociety/ ForSociety-WP1-HU-001-Terminology-a-2005-03-16.pdf. Accessed 19 August 2013

18. Da Costa O, Warnke P, Cagnin C, Scapolo F (2008) The impact of foresight on policy-making: insights from the FORLEARN mutual learning process. Technology Analysis \& Strategic Management 20: 369-387. doi:10.1080/09537320802000146, 1-20

19. Weber KM (2006) Foresight and adaptive planning as complementary elements in anticipatory policy-making: A conceptual and methodological approach. In: Voß JP, Bauknecht D, Kemp R (eds) Reflexive governance for sustainable development. Edward Elgar, Cheltenham, pp 189-221

20. Eriksson EA, Weber KM (2008) Adaptive foresight: navigating the complex landscape of policy strategies. Technol Forecast Soc Chang $75: 462-482$

21. de Burgh H (ed) (2008) Investigative journalism, 2nd edn. Routledge, London, $\mathrm{p} 20$

22. Boyd A (1994) Broadcast journalism. Techniques of radio and television news. Focal, Oxford

23. de Burgh H (ed) (2008) Investigative journalism, 2nd edn. Routledge, London, $p 13$ 
24. Habermas J (1962) Strukturwandel der Öffentlichkeit. Untersuchungen zu einer Kategorie der bürgerlichen Gesellschaft. Suhrkamp, Frankfurt a. M., \$21

25. Lezaun J, Soneryd L (2006) Government by Elicitation: Engaging Stakeholders or Listening to the Idiots?CARR Discussion Papers 34. http://www.lse.ac.uk/researchAnd
Expertise/units/CARR/pdf/DPs/Disspaper34.pdf. Accessed 19 August 2013

26. Bogner A (2012) The paradox of participation experiments. Sci Technol Hum Values 37:506-527

27. Pang ASK (2010) Futures 2.0: rethinking the discipline. Foresight. doi: $10.1108 / 14636681011020191$ 